\title{
IMPACT OF THE ANNUAL TRAINING CYCLE ON THE PHYSICAL CAPACITY OF YOUNG ROWERS
}

\author{
ANDRZEJ KLUSIEWICZ ${ }^{1}$, MARIUSZ SZUMAŃSKI ${ }^{3}$, KAJDA PIOTR, \\ JANINA STARCZEWSKA-CZAPOWSKA ${ }^{1}$, KRYSTYNA BURKHARD- \\ JAGODZIŃSKA ${ }^{2}$, BARBARA DŁUGOŁĘCKA ${ }^{4}$, DARIUSZ SITKOWSKI ${ }^{1}$
}

\author{
Institute of Sport - National Research Institute in Warsaw, Department of Physiology ${ }^{1}$ \\ Sports-Medical Outpatient Clinic ${ }^{2}$, \\ Polish Rowing Association ${ }^{3}$ \\ Józef Piłsudski University of Physical Education in Warsaw, \\ Faculty of Phisical Education and Sport in Biała Podlaska, \\ Department of Physiology and Biochemistry ${ }^{4}$
}

\author{
Mailing address: Andrzej Klusiewicz, Institute of Sport - National Research Institute in Warsaw, \\ Department of Physiology, 2/16 Trylogii Street, 01-982 Warsaw, tel.: +48 22 5699971, fax: +48 22 8350977, \\ e-mail: andrzej.klusiewicz@insp.waw.pl
}

\begin{abstract}
Introduction. The aim of the study was to assess the changes in the physical capacity of a group of leading Polish young male rowers after they completed the annual training cycle. Material and methods. The study involved 30 subjects who either belonged to the Under-23 Polish National Rowing Team or were its reserve rowers. The subjects underwent two stress tests: a maximum intensity test simulating covering the distance of a regatta (the $2 \mathrm{~km}$ test) and a submaximal test with a gradual increase in intensity (the anaerobic threshold test) before and after the annual training cycle. Results. Contrary to what was expected, a year of training did not cause a significant increase in the work capacity indicators measured in the study. The training programme that was implemented was found not to have been very effective in this respect. No statistically significant increase was observed in the values obtained for the subjects in the test simulating covering the distance of the race, although there was some improvement. Conclusions. Similar findings, indicating that the results of stress tests tend to remain stable, were obtained by other authors whose research involved young rowers aged approximately 20 years. However, we would still like to emphasise that the effectiveness of training which develops endurance, the basic foundation for a rower's successful performance, should be paid more attention to in the training process.
\end{abstract}

Key words: young rowers, annual training cycle, changes in physical capacity

\section{Introduction}

Rowing is most frequently described as a sports discipline requiring strength-endurance work [1]. Both male and female rowers need to cover a distance of 2,000 metres during a regatta. Depending on the type of boat and weather conditions, it takes the rowers from 5.5 to 7 minutes to cover this distance, and approximately $70 \%$ of their muscle mass is engaged in the effort [1]. During the race, the rowers reach their maximum aerobic and anaerobic capacities. The rowers' bodies are capable of performing such work thanks to their high mass and metabolic adaptation. It should be emphasised that due to the substantial contribution of aerobic metabolism to the rowers' energy supply during a race (70-80\%), endurance training is considered to be a prerequisite for successful performance in this sports discipline $[2,3,4]$. The training of rowers who achieve superior results, however, not only includes aerobic exercise, but it is also aimed at maintaining a balance between strength training and that focused on developing the athletes' anaerobic capacity $[5,6]$.
It thus seems particularly interesting to investigate the changes in the physical capacity of rowers, especially in that of world-class rowers over a period of several years. Some studies have been conducted with regard to this issue, but these studies typically include senior rowers [7, 8, 9], while there is less research involving young rowers $[10,11]$. In light of the above, the aim of the current study was to assess the changes in the physical capacity of a group of leading under-23 Polish male rowers after the annual training cycle.

\section{Material and methods}

\section{Subjects}

The study involved 30 subjects who either belonged to the Under-23 Polish National Rowing Team or were its reserve rowers. Some basic statistical data regarding selected parameters collected before the annual training cycle are shown in table 1.

The rowers who participated in the study were world-class 
athletes in the sports discipline in their age category. The group of subjects differed in terms of their age, mass, and height, particularly due to the involvement of lightweight rowers in the study. The number of the years of training the rowers had undergone also differed considerably, as it ranged from 2 to 9 years.

Table 1. Basic statistical data of the rowers collected before the annual training cycle $(\mathrm{n}=30)$

\begin{tabular}{|c|c|c|c|c|}
\hline Parameter & $\begin{array}{c}\text { Age } \\
\text { (years) }\end{array}$ & $\begin{array}{c}\text { Body mass } \\
\text { (kg) }\end{array}$ & $\begin{array}{c}\text { Body height } \\
\text { (cm) }\end{array}$ & $\begin{array}{c}\text { Years of } \\
\text { training }\end{array}$ \\
\hline Mean & 19.7 & 84.9 & 190 & 5.1 \\
\hline \pm SD & 0.8 & 9.5 & 6 & 1.6 \\
\hline Min & 18.0 & 70.0 & 178 & 2.0 \\
\hline $\operatorname{Max}$ & 20.8 & 104.8 & 207 & 9.0 \\
\hline
\end{tabular}

\section{Training programme of the Under-23 Polish National Rowing Team}

The 52-week-long annual training cycle, lasting from September to August, was divided into the following four periods: 1) the preliminary period consisting of 8 weekly microcycles (September and October), 2) the preparation period consisting of 27 weekly microcycles (from November to the end of April), 3) the immediate pre-competition period and competition period consisting of 5 and 8 competitive microcycles, respectively (from May to July), and 4) the transition period consisting of 4 weekly microcycles (August). Five training intensity zones were defined based on the following levels of lactate concentration in the blood: $1.5-2.5 \mathrm{mmol} / \mathrm{l}$ - zone $1 ; 2.5-3.5 \mathrm{mmol} / \mathrm{l}$ - zone 2, 3.5-6.0 mmol/l - zone 3, 6.0-12.0 mmol/l - zone 4, and very short supramaximal efforts involving the glycolytic and phosphagen systems - zone 5 .

The preliminary training period was aimed at gradually implementing the training after the transition period. Since during this period the rowers took part in several regattas, such as the Polish Sprint Rowing Championship, Polish Long Distance Rowing Championship, and Main Autumn Polish Qualification Regattas, the training was predominantly specific in nature. During strength training, the rowers developed their strength endurance in order to prepare their muscular systems for han- dling high loads. Over this period 90 hours of work were performed. The rowers rowed for $570 \mathrm{~km}$ in water and for $6 \mathrm{~h} 30$ min (approximately $78 \mathrm{~km}$ ) on a rowing ergometer, as well as doing 10,750 repetitions for strength endurance at the gym. As far as the intensity of the training is concerned, the 90 hours of work were done as follows: 68.5 hours in zone 1, 11 hours in zone 2, 8.5 hours in zone 3 (including 6.5 hours spent on strength training), 47 minutes in zone 4 , and 4 minutes in zone 5 . When it comes to the specificity of the training for the sports discipline, $38.3 \%$ of the training was general in nature $(34.5$ hours), $7.2 \%$ was special training (6.5 hours), and $54.4 \%$ was specific training (49 hours), with the highest level of sportspecificity.

The preparation period was composed of three phases, each lasting 9 weeks: a general training phase, a special training phase, and a specific training phase. The general training phase (November and December) focused on training general strength, building body mass, and developing coordination and general fitness. The weekly microcycles consisted of 3 strength training sessions, one session on a rowing ergometer, as well as running, swimming, general training, and team sports. In the special phase (January and February), the volume and intensity of the work done on the ergometer were increased. The strength training implemented in this phase was aimed at gradually transforming general strength into strength endurance and power. In January, the coaches introduced one training session in strength endurance, one in power, and one in submaximal strength. In February, only strength endurance was trained (in 3 sessions). Moreover, during the winter training camp, a substantial amount of work increasing aerobic endurance was done in intensity zones 1 and 2 (alternate marching and jogging and cross-country skiing). The specific phase of the preparation period (March and April) was aimed at successively introducing specific training in the water, depending on the weather conditions, and improving the rowing technique. The strength training implemented in this phase was aimed at maintaining a high level of strength endurance and power. During the 27 weeks of the preparation period, a total of 360 hours of work were performed, including 253 hours in intensity zone 1, 62 hours in zone 2, 32.5 hours in zone 3 (including 22 dedicated to endurance strength training), 6 hours in zone 4 , and 7.5 hours in zone 5 (including 6.5 hours spent training maximal strength and power). As far as the sport-specificity of the training done during the preparation period is concerned, $66.7 \%$ of the training was general training, $17.4 \%$ was special training, and $15.9 \%$ was specific training.

Table 2. Training programme of the Under-23 Polish National Rowing Team

\begin{tabular}{|c|c|c|c|c|c|c|c|c|c|c|c|}
\hline \multirow[b]{2}{*}{ Period of training } & \multicolumn{3}{|c|}{ Training volume } & \multicolumn{5}{|c|}{ Training intensity zone (hours) } & \multicolumn{3}{|c|}{$\begin{array}{c}\text { Type of training according to } \\
\text { sport-specificity }\end{array}$} \\
\hline & $\begin{array}{l}\text { Number of } \\
\text { repetitions } \\
\text { at the gym }\end{array}$ & $\begin{array}{l}\text { Number of } \\
\text { kilometres }\end{array}$ & $\begin{array}{l}\text { Duration } \\
\text { (hours) }\end{array}$ & 1 & 2 & 3 & 4 & 5 & General & Special & Specific \\
\hline $\begin{array}{c}\text { Preliminary period: } \\
8 \text { weeks (Sept. - Oct.) }\end{array}$ & 10752 & 571 & 90 & 68 & 10 & 9.5 & 1 & 0 & 34.5 & 6.5 & 49 \\
\hline $\begin{array}{c}\text { Preparation period: } \\
27 \text { weeks (Nov.-Apr.) }\end{array}$ & 53835 & 654 & 360 & 253 & 62 & 32.5 & 6 & 7.5 & 240 & 62.5 & 57.5 \\
\hline $\begin{array}{c}\text { Immediate pre-competition and } \\
\text { competition periods: } 5+8 \\
\text { weeks (May-July) }\end{array}$ & 12170 & 1279 & 165 & 141 & 5.5 & 13.5 & 3.5 & 1 & 50 & 2.5 & 112 \\
\hline $\begin{array}{l}\text { Transition period: } \\
4 \text { weeks (Aug.) } \\
\end{array}$ & 0 & 0 & 8.5 & 8 & 0 & 0 & 0 & 0 & 8.5 & 0 & 0 \\
\hline Total & 76757 & 2504 & 624 & 470 & 77.5 & 55.5 & 10.5 & 8.5 & 333 & 71.5 & 218.5 \\
\hline Total (\%) & & & 100 & 76 & 12 & 9 & 2 & 1 & 53 & 12 & 35 \\
\hline
\end{tabular}


The immediate pre-competition and competition periods lasted 5 and 8 weeks, respectively. These two training periods were aimed at aiding the rowers in perfecting their technique and coordination of their movement with that of the rest of the crew, develop their specific speed and endurance, as well as helping them maintain a high level of strength endurance and power. Most of the exercises in these two periods were performed in the water. In order to make sure that the rowers maintained their strength endurance and power, 1-2 training sessions were held per week, depending on the racing schedule. Specific resistance strength training in the water was also implemented. The rowers performed 165 hours of work in these two periods and they rowed for a distance of approximately 1,280 kilometres. As far as the sport-specificity of the training is concerned, specific training accounted for $68 \%$ of the work done in these two periods, while general training constituted $30 \%$ and special training accounted for only $2 \%$ of the work. The immediate pre-competition period consisted of the phases of accumulation (2.5 weeks), intensification (1.5 week), and transformation (1 week).

The transition period was aimed at regeneration and recovery, and it was comprised of general low-intensity training. The rowers had 2-3 training sessions over 4 weeks, and performed 8.5 hours of work.

To sum up, the annual training programme of the Under-23 Polish National Rowing Team consisted of performing 624 hours of work, rowing for a distance of $2,500 \mathrm{~km}$, doing 76,000 repetitions at the gym (including 12,000 for general strength and muscle mass, 6,500 for power, and 57,500 for strength endurance). A total of 472 hours of work were performed in intensity zone 1, 78 hours in zone 2, 55 in zone 3 (including 33 dedicated to endurance strength training), 10 hours in zone 4 , and 8.5 hours in zone 5 (including 6.5 hours spent training maximal strength and power). As far as the sport-specificity of the training done is concerned, 53\% of the work was general training, $12 \%$ was special training, and $35 \%$ was specific training.

\section{Exercise tests}

Before and after the annual training cycle was completed, the subjects underwent two exercise tests: a maximum intensity test simulating covering the distance of a regatta (the 2-km test) and a submaximal test with a gradual increase in intensity (the anaerobic threshold). The tests were conducted in the general phase of the preparation period (November-December), after the study was approved by the Research Ethics Committee of the Institute of Sport - National Research Institute in Warsaw.

\section{2-km test}

The first test to be carried out was the test which simulated covering the distance of 2,000 metres and whose maxi- mum intensity was determined individually for each subject. The subject's goal was to cover the distance of the race in as little time as possible, and the distance which remained to be covered was displayed on the monitor of the ergometer. The test was preceded by an 8-minute warm-up, which consisted of continuous rowing with two 1-minute bouts of acceleration in the 3rd and 5th minute of the warm-up. The pace of continuous rowing was 20 strokes $/$ minute and the power was $2.0 \mathrm{~W} / \mathrm{kg}$, whereas during the acceleration bouts, the pace was 26 strokes/ minute and the power was $2.7 \mathrm{~W} / \mathrm{kg}$. The break between the warm-up and maximal effort was 2 minutes long.

\section{Anaerobic threshold (AT) test}

One day after the 2-km test was conducted, the submaximal test with a gradual increase in intensity was carried out. It consisted of 5 bouts of submaximal effort lasting 3 minutes, with 30 -second breaks. The damper was set to $5-6$. The workload was selected according to table 3 below, taking into account the time it took each open-class rower to cover the distance of $2 \mathrm{~km}$.

Lactate concentration (LA) was measured in blood collected from the earlobe 3 minutes after the subjects completed the 2-km test and immediately after the anaerobic threshold test was completed. The lactate concentrations were determined using an LP 400 photometer (Dr Lange, Germany).

During both tests the subjects' heart rate (HR) was continuously recorded using a Polar Electro Oy S610i heart rate monitor (Finland), and during the $2-\mathrm{km}$ test, lung ventilation, oxygen uptake, and carbon dioxide production were also measured, using the SensorMedics Vmax 29 (Yorba Linda, CA, USA) or the Cortex 3B MetaLyzer (Germany).

The AT test made it possible to determine the anaerobic threshold for each rower using the interpolation method for the blood lactate concentration of $4 \mathrm{mmol} / \mathrm{l}$ [2]. The changes in HR made it possible to calculate the value of the $\mathrm{PWC}_{170}$ index, that is the workload that results in a heart rate of $170 \mathrm{bpm}$ [12]. The $\mathrm{PWC}_{170}$ index was calculated based on the following formula: where:

$\mathrm{PWC}_{170}(\mathrm{~W})=\mathrm{P}_{1}+\left(\mathrm{P}_{2}-\mathrm{P}_{1}\right) \times\left(170-\mathrm{HR}_{1}\right) /\left(\mathrm{HR}_{2}-\mathrm{HR}_{1}\right)$

$\mathrm{HR}_{1}, \mathrm{P}_{1}$ - heart rate below $170 \mathrm{bpm}$ and the power output generated $(\mathrm{W})$,

$\mathrm{HR}_{2}, \mathrm{P}_{2}$ - heart rate above $170 \mathrm{bpm}$ and the power output generated $(\mathrm{W})$.

The tests were conducted at the same time of the day (between 9 a.m. and 2 p.m.) in the same temperature which was optimal for the rowers $\left(18-20^{\circ} \mathrm{C}\right)$, and there were no external sources of disturbance during the test. If the subjects were ill or were recovering from an illness when the measurements were to be carried out, they were not tested.

Table 3. Workload used in the anaerobic threshold test

\begin{tabular}{|c|c|c|c|c|c|c|}
\hline \multicolumn{2}{|c|}{ Workload number } & 1 & 2 & 3 & 4 & 5 \\
\hline \multicolumn{2}{|c|}{ Rowing pace (strokes/minute) } & 16 & 18 & 20 & 22 & 24 \\
\hline Lightweight rowers & \multirow{3}{*}{$\begin{array}{l}\text { Power } \\
\text { (W) }\end{array}$} & 120 & 170 & 220 & 270 & 320 \\
\hline Open-class rowers, $2 \mathrm{~km}>6: 20 \mathrm{~min}$ & & 120 & 170 & 220 & 270 & 320 \\
\hline Open-class rowers, $2 \mathrm{~km}<6: 20 \mathrm{~min}$ & & 170 & 220 & 270 & 320 & 370 \\
\hline
\end{tabular}




\section{Statistical analysis}

The results of the study were analysed statistically. The mean values and standard deviations for selected parameters were calculated. The data were tested for normality of distribution using the Shapiro-Wilk test. Differences between the values obtained were tested for statistical significance using Student's t-test for dependent samples $(\mathrm{p}<0.05)$, and Pearson's correlation coefficient was calculated. The analysis was conducted using Statistica 8 (StatSoft) and Excel 2007 (Microsoft Office).

Table 4. Aerobic capacity indicators measured in the rowers before and after the annual training cycle $(n=30)$

\begin{tabular}{|c|c|c|c|c|c|}
\hline & & \multicolumn{2}{|c|}{ Power at AT } & \multicolumn{2}{c|}{ PWC $_{170}$} \\
\hline & & (W) & (W/kg) & (W) & (W/kg) \\
\hline Pretest & Mean & 295 & 3.48 & 281 & 3.31 \\
\hline & SD & 31 & 0.33 & 47 & 0.55 \\
\hline Posttest & Mean & 295 NSS & 3.44 NSS & 288 Nss & $3.35^{\text {NSS }}$ \\
\hline & SD & 36 & 0.36 & 42 & 0.48 \\
\hline
\end{tabular}

NSS $=$ difference is not statistically significant $(p>0.05)$.

\section{Results}

\section{Changes in physical capacity}

The values obtained for the indicators of aerobic capacity (power at anaerobic threshold and $\mathrm{PWC}_{170}$ ) did not change significantly after the annual training cycle.

Although the indicators used in the 2-km test (time, mean power, and maximal oxygen uptake), which simulated covering the distance of a rowing race, the results tended to improve slightly after a year of training (tab. 5). In the posttest, a significantly higher level of lactate concentration was found in the blood covering the distance of 2,000 metres than in the pretest.

Table 5. Work capacity indicators measured in the rowers before and after the annual training cycle $(n=30)$

\begin{tabular}{|c|c|c|c|c|c|c|c|}
\hline & & \multirow{2}{*}{$\begin{array}{c}\begin{array}{c}\text { Time (needed } \\
\text { to cover } 2 \mathrm{~km} \text { ) }\end{array} \\
\text { (min:s) }\end{array}$} & \multicolumn{2}{|c|}{$\begin{array}{l}\text { Mean } \\
\text { power }\end{array}$} & \multicolumn{2}{|c|}{$\mathrm{VO}_{2} \max$} & \multirow{2}{*}{$\begin{array}{l}\text { Lactate } \\
\text { concen- } \\
\text { tration } \\
\text { (mmol/l) }\end{array}$} \\
\hline & & & (W) & $(W / k g)$ & $(1 / \mathrm{min})$ & $\begin{array}{c}(\mathrm{ml} / \mathrm{kg} / \\
\mathrm{min})\end{array}$ & \\
\hline \multirow[t]{2}{*}{ Pretest } & Mean & $6: 26.6$ & 389 & 4.59 & 5.20 & 61.2 & 15.7 \\
\hline & SD & $00: 11.0$ & 34 & 0.37 & 0.62 & 5.1 & 1.8 \\
\hline \multirow[t]{2}{*}{ Posttest } & Mean & 6:25.1 NSS & $\begin{array}{l}394 \\
\text { NSS }\end{array}$ & $\begin{array}{l}4.60 \\
\text { NSS }\end{array}$ & $\begin{array}{l}5.31 \\
\text { NSS }\end{array}$ & $\begin{array}{l}62.0 \\
\text { NSS }\end{array}$ & $17.0^{*}$ \\
\hline & SD & $00: 10.4$ & 32 & 0.42 & 0.48 & 5.3 & 3.3 \\
\hline
\end{tabular}

NSS $=$ difference is not statistically significant $(p>0.05) ;{ }^{*}$ difference is statistically significant $(p<0.05)$.

Analysing the individual changes in the four basic work capacity indicators per kilograms of body mass obtained for both tests (power at AT, PWC ${ }_{170}$, mean power for the 2-km test, and maximal oxygen uptake), a high percentage of scores were found to have improved and several had deteriorated (tab. 6). The cardiovascular and metabolic response to the load used in the AT test had not improved (fig. 1 and 2).
Table 6. Changes in selected work capacity indicators (in percentages) measured in the rowers before and after the annual training cycle $(\mathrm{n}=30)$

\begin{tabular}{|c|c|c|c|}
\hline & \multicolumn{3}{|c|}{ Percentage (\%) } \\
\hline Indicator Change & Increase & Decrease & $\begin{array}{c}\text { No chan- } \\
\text { ge }\end{array}$ \\
\hline Power at AT $(\mathrm{W} / \mathrm{kg})$ & 37 & 13 & 50 \\
\hline $\mathrm{PWC}_{170}(\mathrm{~W} / \mathrm{kg})$ & 40 & 23 & 37 \\
\hline $2 \cdot \mathrm{km}$ test mean power $(\mathrm{W} / \mathrm{kg})$ & 40 & 27 & 33 \\
\hline $\mathrm{VO}_{2}$ max $(\mathrm{ml} / \mathrm{kg} / \mathrm{min})$ & 40 & 20 & 40 \\
\hline
\end{tabular}

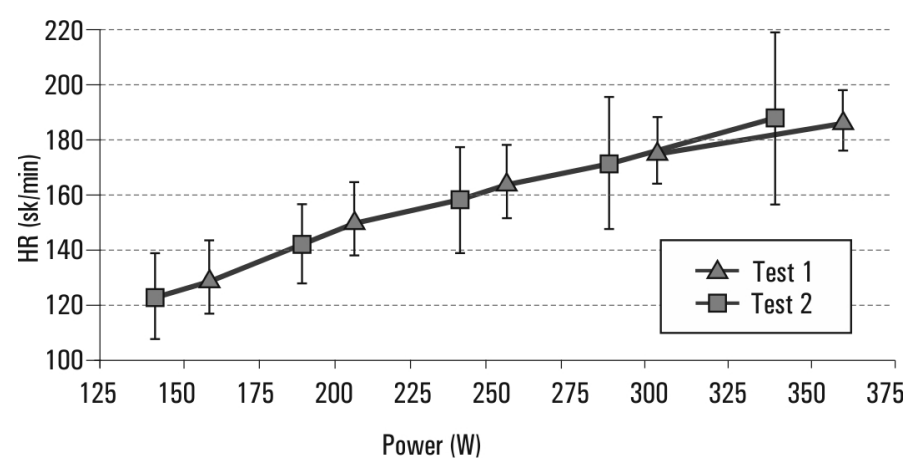

Figure 1. Relationship between heart rate (HR) and power output in the anaerobic threshold test measured in the rowers before and after the annual training cycle $(\mathrm{n}=30)$

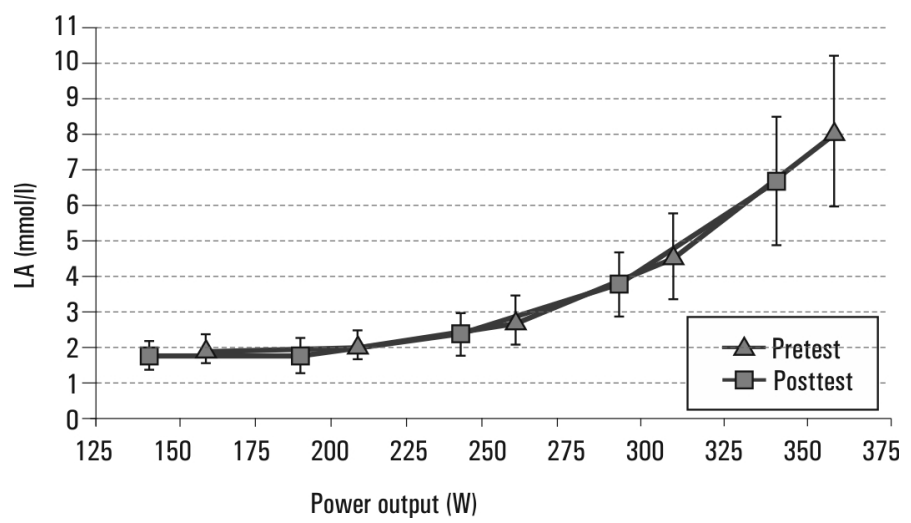

Figure 2. Relationship between lactate concentration (LA) and power output in the anaerobic threshold test measured in the rowers before and after the annual training cycle $(\mathrm{n}=30)$

Table 7. Pearson's correlation coefficient calculated for selected work capacity indicators from the $2-\mathrm{km}$ and AT tests measured in the rowers before the annual training cycle $(\mathrm{n}=30)$

\begin{tabular}{|l|c|c|c|c|c|}
\hline \multicolumn{2}{|c|}{ Indicator } & $\begin{array}{c}2-\mathrm{km} \text { test } \\
\text { mean power } \\
(\mathrm{W} / \mathrm{kg})\end{array}$ & $\begin{array}{c}\text { Power at AT } \\
(\mathrm{W} / \mathrm{kg})\end{array}$ & $\begin{array}{c}\mathrm{PWC}_{170} \\
(\mathrm{~W} / \mathrm{kg})\end{array}$ & $\begin{array}{c}\mathrm{VO}_{2 \mathrm{max}} \\
(\mathrm{ml} / \mathrm{kg}) \\
\mathrm{min})\end{array}$ \\
\hline $\begin{array}{c}2-\mathrm{km} \text { test } \\
\text { mean } \\
\text { power }\end{array}$ & $(\mathrm{W} / \mathrm{kg})$ & - & $0.84^{*}$ & $0.57^{*}$ & $0.65^{*}$ \\
\hline $\begin{array}{c}\text { Power at } \\
\mathrm{AT}\end{array}$ & $(\mathrm{W} / \mathrm{kg})$ & $0.84^{*}$ & - & $0.71^{*}$ & $0.63^{*}$ \\
\hline $\mathrm{PWC}_{170}$ & $(\mathrm{~W} / \mathrm{kg})$ & $0.57^{*}$ & $0.71^{*}$ & - & $0.56^{*}$ \\
\hline $\mathrm{VO}_{2} \mathrm{max}$ & $(\mathrm{ml} / \mathrm{kg} / \mathrm{min})$ & $0.65^{*}$ & $0.63^{*}$ & $0.56^{*}$ & - \\
\hline
\end{tabular}


The highest statistically significant differences were obtained between mean power in the $2-\mathrm{km}$ test and power at AT $(\mathrm{r}=0.84)$, power at AT and $\mathrm{PWC}_{170}(\mathrm{r}=0.71)$, mean power in the $2-\mathrm{km}$ test and $\mathrm{VO}_{2} \max (\mathrm{r}=0.65)$, power at AT and $\mathrm{VO}_{2} \max (\mathrm{r}=0.63)$, and finally mean power in the $2-\mathrm{km}$ test and $\mathrm{PWC}_{170}(\mathrm{r}=0.57)$, as shown in table 7 .

\section{Discussion}

Two types of stress tests were used in the current study involving leading Polish under-23 rowers: one with maximum intensity and one with a gradual increase in intensity. These tests, though in slightly different forms, have been routinely used for more than a decade in diagnosing the work capacity of rowers [13]. According to several authors [15, 16, 17], using the two stress tests makes it possible to fully examine a rower's physical capacity.

A previous study we conducted [12] confirmed that $\mathrm{PWC}_{170}$ measured for specific effort in tests conducted using a rowing ergometer differs considerably between rowers depending on their performance (higher values are achieved by rowers who are successful in competitions). The study also revealed a high correlation between PWC $_{170}$ and the following: mean power generated in the racing distance, power at anaerobic threshold, and maximal oxygen uptake. Other authors [10] have also found significant correlations between $\mathrm{PWC}_{170}$ and mean power in a $2-\mathrm{km}$ distance. In light of the results of research presented above and the fact that $\mathrm{PWC}_{170}$ can be easily measured by the rowers' coach, we recommend that this index be used to assess the work capacity of rowers, especially young ones. $\mathrm{PWC}_{170}$ values obtained for other rowers in previous years may be used as a point of reference for assessing a rower's physical capacity [12].

Contrary to what was expected, a year of training did not cause a significant increase in the work capacity indicators measured in the current study. Power at the anaerobic threshold did not improve significantly, and a lack of improvement of the rowers' aerobic capacity is confirmed by the fact that the remaining cardiorespiratory indicators $\left(\mathrm{VO}_{2} \max\right.$ and $\left.\mathrm{PWC}_{170}\right)$ did not change significantly. Similarly, in another study, which lasted 6 years and involved some leading young rowers [11], it was found that power at AT decreased by $2 \%$ by the time the rowers were 20 years old. The work capacity of an Under-23 rower is mostly determined by the level of their aerobic capacity, which is proven by the strong correlation between mean power in a distance of $2,000 \mathrm{~m}$ and the values obtained for power at AT ( $\mathrm{r}=0.84), \mathrm{VO}_{2} \max (\mathrm{r}=0.65)$, and $\mathrm{PWC}_{170}(\mathrm{r}=0.57)$ found in the study. The data we obtained indicate that more emphasis should be laid on developing the rowers' aerobic capacity in their future training, and both the volume and intensity of the exercise they perform are of importance in this respect. These findings are similar to those of previous studies involving young rowers we have conducted, where a higher increase in the indicators of work capacity was noted for younger juniors compared to older juniors, although the need to work on developing better power at AT in both groups was emphasised [13]. Buśko et al. [10], who carried out a study involving young juniors, also did not observe an improvement in aerobic capacity assess based on PWC $_{170}$ measured for specific effort performed on a rowing ergometer in the general phase of the preparation period (November compared to March). Contrary to the findings our research, however, the authors quoted above established that there had been an increase in mean power and time in the test simulating covering the distance of 2,000 m performed on a rowing ergometer. An improvement in the results obtained for younger juniors (16.7 \pm 0.4 years) and lack of improvement in those recorded for older juniors (19.7 \pm 0.8 years) found in our previous study [13] are in line with the findings of research involving superior Croatian rowers, according to which maximal oxygen uptake tends to stabilise around the age of 20 years [11]. Other research conducted on world-class rowers [17] showed that $\mathrm{VO}_{2} \max$ reaches its peak when the rowers are 23 years old and increases only slightly until the age of 28 years. A similar tendency was observed in leading runners aged 20-22 years [18]. Lacour et al. [9] also mention the fact that work capacity and $\mathrm{VO}_{2}$ max tend to decrease in long-distance runners and swimmers when they are 20-25 years old. Taking this into consideration, the results of an outstanding senior rower whose maximal oxygen uptake increased until he reached the age of 32 years [9] are an exception to the general tendency observed in this respect.

The ability of the body of a rower to perform effort involving a high proportion of glycolytic metabolism is not the most important factor impacting the results of the test that simulates covering the distance of the regatta [13]. However, it should be stressed that the increase in lactate concentration measured after the test from $15.7 \pm 1.8$ to $17.0 \pm 3.3 \mathrm{mmol} / \mathrm{l}$ after the rowers completed the annual training cycle proves that their capacity for maximal effort had increased.

In a cross-sectional study we conducted in previous years, we examined 305 Polish male and female rowers in terms of their physical capacity, considering their age category, outstanding achievements, and their qualification for the national team [19]. In the study we determined that the following indices characterise superior rowers: mean power and time in the test simulating covering the racing distance, power at AT, $\mathrm{VO}_{2}$ max, and maximal oxygen pulse. Based on the results of the study, referential values for the indices which are the most important for assessing the physical capacity of rowers were provided. It is worth mentioning that a strong correlation was found between $\mathrm{VO}_{2}$ max and the time needed to cover the distance of the regatta, as observed in other studies $[6,16]$. In other research [11], world-class rowers were found to exhibit a systematic and high $(26 \%)$ increase in maximal oxygen uptake up to the level of $6.6 \mathrm{l} / \mathrm{min}$ (approximately $70 \mathrm{ml} / \mathrm{kg} / \mathrm{min}$ ) over a 6-year period of assessment which started when the rowers were 16 years old. Based on their several-year study involving an outstanding senior rower who won seven medals at the Olympics and World Championships, Lacour et al. [9] postulated that superior results in rowing are achieved thanks to the rower's capacity to maintain a high level of maximal oxygen uptake (approximately $6.0 \mathrm{l} / \mathrm{min}$ ) and power in the final phase of the test with a gradual increase in intensity performed on a rowing ergometer. As mentioned earlier, an additional feature of the exceptional rower examined in the study was his ability to deal with high loads up to the age of 32 years.

To sump up, the programme implemented in the annual training cycle of the Under-23 rowers who participated in the current study aimed at improving their aerobic capacity was found not to have been very effective in this respect. Despite the fact that many studies $[11,13]$ have proven that the results of stress tests carried out in young rowers tend to become stable when they are approximately 20 years old, we have stressed the need to pay more attention to the effectiveness of endurance training, which is a basis for the rower's successful physical performance.

\section{Acknowledgements}

The authors of the publication would like to thank the rowers for participating in the study as well as the " $\mathrm{VO}_{2}$ max" Technologies for providing technical support during the measurements performed herein. Some of the findings of the study are presented in Piotr Kajda's Master's thesis. 


\section{Literature}

1. Steinacker J.M. (1993). Physiological aspects of training in rowing. International Journal of Sports Medicine 14, 3-10.

2. Howald H. (1988). Physiological foundations of rowing performance. In Steinacker J.M. (ed.) Rowing. Sports Medicine and Science (pp. 31-38). Berlin, Heidelberg: Springer. [in German]

3. Secher N.H. (1993). Physiological and biomechanical aspects of rowing. Implications for training. Sports Medicine 15, 24-42.

4. Steinacker J.M. (1988). Methods for performance assessment and training management in rowing and their application. In Steinacker J.M. (ed.) Rowing. Sports Medicine and Science (pp. 31-38). Berlin, Heidelberg: Springer. [in German]

5. Klusiewicz A., Trzaskoma Z., Broniec J., Wojciechowski A. (2012). Fundamental principles of training elite rowers. Part 1 - training programmes and methods. Sport Wyczynowy 1, 8-16.

6. Mäestu J., Jürimäe J., Jürimäe Y. (2005). Monitoring of performance and training in rowing. Sports Medicine 35(7), 597-617.

7. Fiskerstrand Å., Seiler K.S. (2004). Training and performance characteristics among Norwegian International Rowers 1970-2001. Scandinavian Journal of Medicine $\mathcal{\sigma}$ Science in Sports 14, 303-310.

8. Klusiewicz A., Broniec J., Szczepańska B., BurkhardJagodzińska K. (2002). Physical capacity and body composition of Olympic rowing champions in lightweight double sculls over six years of training. Sport Wyczynowy 5-6, 5167.

9. Lacour J.R., Messonnier L., Bourdin M. (2009). Physiological correlates of performance. Case study of a world-class rower. European Journal of Applied Physiology 106, 407413.
10. Buśko K., Wit B., Borys R. (2002). Selected physiological variables during the preparatory period in junior rowers. Physical Education and Sport 46(3), 375-385.

11. Mikulic P. (2011). Maturation to elite status: a six-year physiological case study of a world champion rowing crew. European Journal of Applied Physiology 111, 2363-2368.

12. Klusiewicz A., Faff J., Zdanowicz R. (1997). The usefulness of PWC170 in assessing the performance determined on a rowing ergometer. Biology of Sport 14, 127-133.

13. Klusiewicz A., Borkowski L., Ładyga M., Zdanowicz R., Burkhard-Jagodzińska K., Sitkowski D. et al. (1994). Changes in physical fitness of male and female junior rowers as affected by one year of training. Biology of Sport 11, 21-29.

14. Kennedy M.D., Bell G.J. (2003). Development of race profiles for the performance of a simulated 2000-m rowing race. Canadian Journal of Applied Physiology 28(4), 536546.

15. Steinacker J.M., Lormes W., Stauch M. (1991). Sport Specific Testing in Rowing. In N. Bachl, T.E. Graham, H. Lollgen (eds) Advances in Ergometry (pp. 443-454). SpringerVerlag.

16. Yoshiga C.C., Higuchi M. (2003). Rowing performance of female and male rowers. Scandinavian Journal of Medicine and Science in Sports 13, 317-321.

17. Messonnier L., Bourdin M., Lacour J.R. (1998). Influence of age on different determining factors of performance on rowing ergometer. Science in Sports 13, 293-294.

18. Legaz Arrese A., González Badillo J.J., Serrano Ostáriz E. (2005). The changes in running performance and maximal oxygen uptake after long-term training in elite athletes. Journal of Sports Medicine and Physical Fitness 45(4), 435440.

19. Klusiewicz A., Faff J., Zdanowicz R. (1997). Physical capacity of Polish female and male rowers. Sport Wyczynowy 9-10, 35-40.

Submitted: June 24, 2015

Accepted: December 19, 2015 